\title{
Participação popular na formação do comitê de equidade em saúde na cidade de Goiás, Goiás.
}

Popular participation in the formation of health equity committee in the city of Goiás, Goiás. La participación popular en la formación del comité para la equidad en salud en la ciudad de Goiás, Goiás

\section{Fernanda Sousa Oliveira ${ }^{1}$}

Resumo: A pesquisa teve por objetivos analisar a participação no processo de implementação dos Comitês de Equidade do SUS, após a roda de diálogos, na Cidade de Goiás, no Estado de Goiás, e verificar se a participação pode ser critério para o empoderamento dos sujeitos. Por meio de estudo de caso, a pesquisa buscou compreender como vem se constituindo a participação a partir da experiência desenvolvida no Projeto de Extensão 'Saberes, Fazeres e Sabores: práticas integrativas da Política Nacional de Educação Popular em Saúde e articulações no Centro-Oeste'. Foi realizada grupo focal com os participantes da Roda de Conversa. Os resultados indicam que a concepção de participação está relacionada à ideia de reunião de pessoas com interesses comuns e contribui para o exercício do direito à saúde. Entretanto, as características históricas e culturais do Estado de Goiás e da Cidade de Goiás foram apontadas como elementos limitantes para o desenvolvimento da participação popular e para o processo de constituição do Comitê de Equidade. Nesse sentido, a Roda de Conversa foi apontada como importante para o avanço da participação popular, por ser um espaço de aquisição de conhecimentos e informações e, portanto, adquire característica de espaço de formação sobre as questões relacionadas à saúde.

Palavras-chave: Participação, Democracia, Educação, Políticas de Saúde

\begin{abstract}
This research aimed to examine the participation in the implementation of the SUS's Equity Committees in the City of Goiás, in the state of Goiás, and verify if this participation can be criteria for the empowerment of individuals. Through a case study, the research sought to understand how the improvement of participation from the experience developed in the Extension Project "Knowledge, Doings and Flavors: integrating practices from the National Public Education in Health and relations in the Midwest". A focal group was conducted with participants through a round-table session. The results indicate that the concept of participation is related to the idea of meeting people with common interests and contribute to the exercise of the right to health. However, the historical and cultural characteristics of the state of Goiás and the City of Goiás were identified as limiting elements for the development of public participation and the process of establishment of the Equity Committee. In this sense, the round-table was identified as important to advancement of public participation, for being a moment of acquiring knowledge and information and thus securing discussions on training issues related to health.
\end{abstract}

Keywords: Public Participation, democracy, Popular Education, Health Policies

Resumen: Esta investigación tuvo como objetivo examinar la participación en la implementación de los Comités de renta variable del SUS en la ciudad de Goiás, en el Estado de Goiás que pudo verificar que la participación puede ser un criterio para el

\footnotetext{
${ }_{1}^{1}$ Mestre em Sociologia. Conciliadora da 13aㅡ Vara do Juizado Especial Cível da Justiça Federal em Goiânia. Advogada. Professora do curso de Direito da Universidade Federal de Goiás. E-mail: fsoliviere@yahoo.com.br
} 
empoderamiento de los individuos. A través del estudio de casos, la investigación trató de entender cómo llegar a la participación de la experiencia desarrollada en el Proyecto de Extensión " de conocimiento, hechos y Sabores: prácticas integradoras de la Educación Popular en Salud y articulaciones en el Medio Oeste". Fue hecho un grupo focal con los participantes por ruedas de conversación. Los resultados indican que el concepto de la participación se relaciona con la idea de conocer a personas con intereses comunes y que esa participación puede mejorar al ejercicio del derecho a la salud. Sin embargo, las características históricas y culturales del estado de Goiás y de la Ciudad de Goiás fueron identificadas como limitantes para el desarrollo de la participación popular y el proceso de establecimiento de los miembros del Comité de Equidad. En este sentido, la charla dentro de la rueda fue identificada como importante para avanzar en la participación popular, siendo un sitio de adquisición de conocimientos e información y por lo tanto un espacio para la formación en temas de salud.

Palabras-Ilave: Participación, Democracia, Educación. Políticas de Salud

\section{Introdução}

A participação é um instrumento de soberania popular que aparece na arena política como um elemento de controle e de exercício de cidadania. Contudo, nesse mesmo contexto político, existem divergências no que tange aceitação ou não da participação do povo nas decisões políticas das mais diversas áreas.

Atualmente, vem sendo desenvolvida a Política Nacional de Educação Popular em Saúde, a qual se articula ao processo de constituição de Comitês de Equidade em Saúde. Tais Comitês preveem a participação da sociedade civil organizada a partir de movimentos sociais visando focalizar questões da saúde advindas das demandas e das especificidades dos negros, dos povos do campo e da floresta, dos ciganos, dos moradores de rua e das lésbicas, gays, bissexuais, travestis, transexuais e transgêneros (LGBTT).

O presente trabalho apresenta os resultados de um estudo de caso que tentou compreender a constituição da participação popular e do empoderamento dos sujeitos no processo de formação dos Comitês de Equidade em Saúde, na cidade de Goiás, a partir da experiência desenvolvida no Projeto de Extensão 'Saberes, Fazeres e Sabores: práticas integrativas da Política Nacional de Educação Popular em Saúde e articulações no CentroOeste'.

$\mathrm{Na}$ modernidade, a participação vem sendo forjada a partir da organização e mobilização dos diversos seguimentos que compõem a classe trabalhadora e, também, dos grupos de indivíduos excluídos. Tal participação contribui para a constituição das bases teóricas da democracia na modernidade. 
A participação, desde então, assume, gradativamente, um lugar na esfera política. Mas, esse lugar não está consolidado, tampouco livre de confrontos.

Em, 'Participação e Democracia', Patemam (1) apresenta duas perspectivas de participação no contexto democrático. Uma denominada de teoria elitista e outra de teoria participativa. Na primeira, a sociedade somente tem condições de manter o equilíbrio porque existe um restrito grupo no comando político, que possui condições adequadas para gerir e lidar com as adversidades sociais.

Tais condições podem estar relacionadas à superioridade psicológica do grupo dominante sobre os dominados (2); as condições técnicas que limitam a participação direta da população uma vez que esta não é capaz nem de se autogerir, que dirá gerir a sociedade (2). E, por fim, uma condição de representação indireta, mediada pela escolha a partir do sistema eleitoral. Neste caso, a participação está tolhida e restrita ao voto (2).

Costa (3) analisa a essência da teoria elitista e corrobora a ideia trazida por Pateman (1). Para ela, a democracia permanece a mesma, mas, a participação estaria reduzida ao ato de votar, a partir das definições estabelecidas pelas elites, num contexto onde igualdade não prevaleceria devido à impossibilidade natural de sua ocorrência.

Da teoria elitista à teoria pluralista de Robert Dahl (4) é possível verificar que foi colocado a existência de várias minorias no controle das decisões políticas e que, por vezes, essas minorias atuavam em lugares distintos produzindo uma oposição.

Também estabeleceu a ideia de poliarquia, ou seja, forma de democracia baseada na multiplicidade de governo que teria algumas garantias para promover a governabilidade, tais como: direito de votação, eleições livres e liberdade de expressão.

A ideia de participação em Dahl (4) está pautada no argumento de que quanto mais baixa for a renda, o sujeito menos politizado será, contudo, proporcionalmente, será maior a propensão para o autoritarismo. Aponta para o declínio da poliarquia caso haja maior inserção de participação do homem comum.

A evolução histórica da construção do significado para participação indicou, até o presente momento, que, culturalmente, a democracia forjada nas mais distintas sociedades tem sido um elemento para manutenção do poder de minorias isoladas ou uma coletividade de minorias com interesses e projetos próprios.

A participação está reduzida ao sistema eleitoral, ou seja, a partir das escolhas que o eleitor deverá fazer dentro de um limitado número de candidatos com condições de 
elegibilidade. O estado de competição instaura-se e o eleitor deve definir quais serão os representantes que atuarão no contexto político.

Pateman (1) analisou também a segunda teoria - democracia participativa, cujo autor principal é Rousseau. Para ela, esse autor teve um significado singular no debate sobre a participação, porque defende um efeito psicológico sobre os que participam, assegurando uma inter-relação contínua entre o funcionamento das instituições e as qualidades e atitudes dos indivíduos.

Nesta teoria, revelam-se dois importantes elementos para o melhor entendimento do significado de participação, o primeiro é a questão da igualdade e o segundo perpassa pela independência econômica dos sujeitos. Existe aqui, o estabelecimento de uma relação de interdependência, onde 'haverá uma dependência de cada indivíduo em relação aos outros' (1).

A participação exerceria algumas funções básicas no contexto democrático, tais como: educativo, integrativa e de controle. Destaca-se a função educativa, como a tomada de consciência coletiva dos sujeitos ao ponto de reconhecerem-se num processo de discussão de interesses ampliados.

À medida que se participa se cria, culturalmente, o compromisso com as demandas sociais, surge, então, a função de controle. Por fim, a integratividade da participação denota uma inter-relação ente as outras duas funções no sentido de consolidar o processo de formação dos sujeitos para o exercício da participação, assim como para a produção da igualdade (1).

Outro autor que se propôs ao estudo da participação foi Pedro Demo (5). Para ele, a participação como metodologia apresenta alguns elementos bem definidos para a consecução dos seus objetivos: a autopromoção, a realização da cidadania, a implementação de regras democráticas de jogo, controle do poder, controle da burocracia, negociação, cultura democrática.

Por autopromoção, o autor entende ser um instrumento de contribuição para a independência dos sujeitos da política assistencialista, bem como, contribuir com a mitigação dos nefastos efeitos residuais, compensatórios e emergenciais que o caracterizam.

Por realização da cidadania, Demo (5) assume o posicionamento de que, assim como a participação, a cidadania tem sido construída ao longo dos tempos, tornando-se uma conquista. Seu significado aduz à organização da sociedade em torno de direitos e deveres 
amplamente reconhecidos e pressupõe a igualdade e a aceitação dos direitos humanos como direitos inalienáveis.

A implementação das regras do jogo revela a necessidade de haver formação para o exercício da participação, empoderar os sujeitos para que tenham discernimento para a crítica, para a avaliação do processo político que está instaurado ou prestes a ser instaurado. Além do mais, as pessoas devem estar dispostas ao enfrentamento com o jogo da participação dentro do contexto da democracia.

Sobre o controle do poder, o autor destaca que dentro de espaços democráticos ele se realiza por meio do sistema de sufrágio, onde o voto é elemento preponderante no controle do poder. Todavia, indica que não é plenamente eficaz, devendo operar outras formas de controle como as redes de organizações da sociedade civil e a mídia não tendenciosa.

Outro controle apresentado no texto de Demo é o da burocracia, esse fenômeno estatal é tratado no texto como prejudicial ao corpo social, mas passível de ter suas ações revertidas em benefício da sociedade, desde que haja mobilização, cobranças e constante vigilância sobre o trabalho da burocracia estatal. "Uma sociedade organizada e participativa, porém, não tolera vícios, porque tem consciência de que a burocracia é mantida com o trabalho e a produção da sociedade" (5).

Demo entende a negociação como o tratamento dos conflitos sobre o pressuposto da igualdade. É um exercício constante de acomodação das divergências em graus passíveis de estabelecer o convívio e a realização minorada, relativa dos interesses em disputa.

A cultura democrática está, ao lado do controle do poder, dentre os objetivos de maior peso para o exercício da participação. Ao se naturalizar emergirão todos os outros objetivos conjuntamente, os espaços públicos serão marcados pela acessibilidade aberta, por uma burocracia comprometida com os interesses internos e externos, a negociação como elementos dinamizador de resolução de conflitos.

\section{A Participação e a Política de Educação Popular em Saúde}

A participação aparece no contexto da Política Nacional de Educação Popular em Saúde como um eixo estratégico, um elemento capaz de, desde um processo educativo, contribuir para a promoção da emancipação dos sujeitos. 
O Projeto Democrático e Popular promotor de vida e saúde caracteriza-se por princípios como a valorização do ser humano em sua integralidade, a soberania e autodeterminação dos povos, o respeito à diversidade étnicocultural, de gênero, sexual, religiosa e geracional; a preservação da biodiversidade no contexto do desenvolvimento sustentável; o protagonismo, a organização e o poder popular; a democracia participativa; organização solidária da economia e da sociedade; acesso e garantia universal aos direitos, reafirmando o SUS como parte constitutiva deste Projeto. (6)

Participar, no contexto da educação popular em saúde é estar presente, compartilhar as demandas e as formas como serão encaminhadas as possíveis soluções para tais demandas. Participar é envolver-se, solidarizar-se é enfrentamento constante entre sujeitos com interesses distintos, é um pressuposto para a construção de um pacto social capaz de promover o bem comum.

A fim de que, pois, o pacto social não seja um vão formulário, ele encerra tacitamente este ato, que só pode dar força aos outros, recusando-se a obedecer à vontade geral e será constrangido por todo o corpo, o que significa senão que o forçarão a ser livre, pois tal é a condição que, dando cada cidadão à Pátria, garante-lhe toda a dependência pessoal; condição que faz o artificio e o jogo da máquina política e que só torna legítimos os atos civis, os quais, sem isso seriam absurdos, tirânicos e sujeitos aos maiores absurdos. (7)

Ao produzir uma política, importante se faz indicar o elemento participação como fundamental para a consecução dos objetivos precípuos que a orientam, ao fazer constar esse elemento, abre-se caminho para a construção de uma sociedade mais justa e equânime.

Contudo, não basta apenas apresentá-la como componente fundamental das políticas deve-se criar condições de efetiva promoção da formação e do exercício da cidadania por meio do participar. A Política Nacional de Educação Popular e Saúde aponta, acertadamente, para a criação de espaços produtores de reflexão e formação dos sujeitos.

\section{Objetivos}

Como Estudo de Caso, esta pesquisa objetivou compreender como vem se constituindo a participação popular no processo de formação dos Comitês de Equidade em Saúde na Cidade de Goiás, a partir da experiência desenvolvida no Projeto de Extensão 'Saberes, Fazeres e Sabores: práticas integrativas da Política Nacional de Educação Popular em Saúde e articulações no Centro-Oeste'. 


\section{Metodologia}

Foi realizado um estudo de caso. Conforme Yin (8), estudo de caso é uma pesquisa empírica aplicável quando se pretende:

Explicar ligações causais em intervenções ou situações da vida real que são complexas demais para tratamento, por meio de estratégias experimentais ou de levantamento de dados; descrever um contexto de vida real no qual uma intervenção ocorreu; avaliar uma intervenção em curso e modificá-la com base em um Estudo de Caso ilustrativo; explorar aquelas situações nas quais a intervenção não tem clareza no conjunto de resultados. (8)

Considerou-se adequado a este tipo de pesquisa, por possuir, o problema de pesquisa e o objeto, as seguintes características:

1. O problema de pesquisa buscou responder ao 'como', ao processo pelo qual vem se desenvolvendo a participação popular;

2. O objeto de pesquisa - constituição da participação popular para formação dos Comitês de Equidade em Saúde em Goiás - demandou esclarecimentos, por exemplo, sobre as decisões tomadas, as estratégias de mobilização e participação popular, como vêm se constituindo a implementação do Comitê de Equidade em Saúde, quais resultados têm sido alcançados do ponto de vista da potencialização da participação no processo de constituição do referido Comitê na Cidade de Goiás, em Goiás.

A constituição da participação popular para a formação do Comitê de Equidade em Saúde na Cidade de Goiás é um caso significativo de estudo, primeiramente, porque tal participação foi fomentada pela ação de um Projeto de Extensão desenvolvido pela Universidade Federal de Goiás, mas construído a partir da participação de integrantes de movimentos sociais diversos, em especial do campo da saúde. Em segundo lugar, porque se trata de uma parceria sociedade-universidade para implementação de Comitês de Equidade em Saúde, que prima pela participação popular ativa, considerando seus saberes, suas experiências, suas demandas, suas formas organizativas e reivindicativas.

Os instrumentos para coleta de dados foram:

- Grupo Focal com os membros da comissão criada na Roda de Conversa para mobilização e criação do Comitê de Equidade em Saúde na Cidade de Goiás, Goiás;

- Entrevista com representante da Articulação Nacional de Educação Popular em Saúde. 
A coleta de dados foi realizada a partir do contato com os membros da comissão para mobilização e criação do Comitê de Equidade em Saúde, bem como representante da Articulação Nacional de Educação Popular em Saúde com entrevistas. Os contatos ocorreram entre os meses de julho e setembro de 2014, na Cidade de Goiás. O roteiro construído teve por perguntas básicas:

1. O que é participação popular para você?

2. A participação pode contribuir para o exercício do direito à saúde?

3. Como está sendo desenvolvido o trabalho da comissão para mobilização e criação do Comitê de Equidade em Saúde?

4. Como você avalia a participação popular e o exercício da cidadania na Cidade de Goiás?

5. Para você, qual a contribuição da roda de conversa?

\section{Resultado e Discussão}

Dos oito colaboradores previstos inicialmente, foi possível estabelecer o grupo focal com seis colaboradores, sendo um representante da ANEPS-Goiás e cinco agentes de saúde. Destes cinco, um era membro da comissão constituída para construir o Comitê de Equidade na Cidade de Goiás.

Considerou-se que o período eleitoral influenciou sobremaneira, pois todos integrantes da comissão são lideranças locais e estiveram envolvidos com a campanha para eleição de representantes para Senado, Câmaras Federal e Estadual, Governo Estadual e Presidente do Brasil.

A análise está dividida em três momentos:

1. Características e condições da participação popular na Cidade de Goiás e no Estado de Goiás.

2. Concepção sobre participação popular e sua relação com o exercício da cidadania e do direito à saúde.

3. Contribuição da Roda de Conversa para a construção da participação popular em saúde na Cidade de Goiás. 


\section{Características e condições da participação popular na Cidade de Goiás e no Estado de Goiás}

Sobre a participação popular no Estado de Goiás e na Cidade de Goiás foi possível identificar dois eixos de reflexão sobre o tema. No primeiro, um grupo de colaboradores afirmaram que a participação popular é incipiente e não tem se desenvolvido. Apontam, em certo sentido, que há uma paralisia, inclusive, de movimentos sociais que outrora foram mais atuantes, como o Movimento dos Trabalhadores Rurais Sem Terra (MST).

Sim, eu já conheço um pouco desses movimentos, eu vim do movimento dos produtores rurais. Com essa participação é possível sim. Só que essa participação não têm se desenvolvido na cidade. (P2)

Tá faltando mais empenho nesse movimento. Dos profissionais da saúde que deveriam estar se movimentando, mas não estamos vendo a mobilidade. $O$ MST deveria estar se mobilizando, os movimentos sociais também. Mas pararam no tempo. Assim a participação popular não vai pra frente. (P1)

Eu avalio de uma forma assim, hum [...] $50 \%$, temos uma população muito ativa, procurando seus direitos, reivindicando, mas infelizmente ainda têm muitas pessoas que estão um pouco paralisadas, elas sentem a necessidade, as vezes reclamam, mas as vezes falta iniciativa. (P5)

No segundo eixo, outros colaboradores afirmam que a participação popular ainda é limitada e deve ser desenvolvida. Entretanto, não a consideram inerte, tendo em vista as características históricas do Estado de Goiás e da Cidade de Goiás.

Analiso a partir de uma conjuntura que estamos vivendo no atual momento de que a participação popular ela existe, porém está tímida. Muitos são os desafios e nem sempre há conquistas. No entanto, percebo muita gente, muitos movimentos com coragem e com vontade de fazer acontecer a diferença. Mas em Goiás, temos uma característica diferente de outras regiões do Brasil em que há uma maior atuação dos movimentos. (P3)

Um colaborador vinculado ao segundo eixo de reflexão indica que, na Cidade de Goiás, a participação está começando a se desenvolver devido às mudanças de mentalidade promovidas pela educação, em particular a desenvolvida no interior da Universidade. Isto tem produzido superação da cultura coronelista.

Hoje ela tá começando a fluir, mas antes era muito arraigado, por que por nós vivemos em uma cidade que vem de uma tradição de coronelismo, e assim as pessoas têm medo de buscar, por que sempre foi aquela questão do cabresto, por que você não pode reivindicar por quê? Por que amanhã você 
pode precisar daquela pessoa. Então hoje com essa vinda das faculdades, com essa vinda da universidade para a comunidade, têm mudado muito a cabeça das pessoas, por quê? Porque hoje elas podem ver que com o estudo elas podem ir muito além, não precisam ficar presos no cabresto de um patrão, no cabresto de que você deve votar em fulano, aquela questão do coronel mesmo, questão de mandar, infelizmente ainda têm muito isso. Mas hoje tá mudando com toda essa educação que tá vindo, digo educação em geral, não tô focando que as pessoas não eram educadas não!! Tô dizendo que isso mudou muito por que as pessoas hoje são mais esclarecidas, essa é a participação popular, você está tendo direito de escolher o seu candidato, está tendo o direito de buscar, de ir á rádio e reclamar e isto vai ser melhor para a população, e os nossos filhos estão vindo com mentalidade diferente da nossa!! (P6)

Diante dos dois eixos de reflexão, pode-se inferir que na Cidade de Goiás respeitadas as peculiaridades locais e regionais, identifica-se certo enfraquecimento e esvaziamento da participação popular organizada nos movimentos sociais historicamente consolidados.

Ao mesmo tempo, os colaboradores destacam a pujança da educação como elemento mobilizador da participação popular e do livre exercício da cidadania. Isto será evidenciado novamente quando da análise sobre a contribuição das rodas de conversa para a participação popular.

O representante da Articulação Nacional de Movimentos e Práticas de Educação Popular e Saúde (ANEPS-GO), ao ser questionado sobre o papel desta Associação na construção da participação popular em Goiás, destaca a centralidade do seu papel formativo deste movimento social.

A ANEPS assim como qualquer outro movimento que se propõe a trabalhar a pedagogia popular freireana tem o papel de promover nos pequenos grupos onde ela atua a discussão, elaboração e propositura de repostas para situações limites. Para uma ampliação maior desses resultados a ANEPS tem como papel o de articular e juntamente com outros movimentos que compõem a RECID-GO de construir coletivamente o que sonhamos que o Brasil Popular. (P3)

Destaca, ainda, que a política de educação popular em saúde potencializa a participação quando propõe novas metodologias que valorizam saberes e fazeres de diferentes grupos e, por meio disto, qualificam os relacionamentos humanos.

Acredito que [a política de educação popular em saúde] potencializa na medida em que propõem novas metodologias, novas abordagens, e novas formas de se relacionar enquanto ser humano. A partir dos princípios orientadores do SUS e da humanização, valorizando os saberes e fazeres 
dos grupos diversos seja do campo ou da floresta, negros ou LGBT, indígenas ou ciganos etc. (P3) (colchetes nossos)

Na cidade de Goiás, o exercício da participação, ao exemplo de todo o Estado goiano, esteve subjugada pela proposta política do coronelismo. A voz popular era representada pelo chefe local que pactuava com o governo estadual e federal na medida dos seus interesses. A saúde, a educação, e a independência econômica dos trabalhadores estavam condicionadas a autoridade do coronel.

Essa situação demonstra que, historicamente, em Goiás, houve pressões diversas para fortalecer e manter o controle da região. Pateman (1) indica que 'aprendemos participar participando e de que o sentimento de eficácia tem mais probabilidades de se desenvolver em um ambiente participativo'. Ora, em Goiás não se exercitou a participação, tampouco houve a construção de um ambiente que estimulasse o exercício de participar.

Para o sujeito P5, na cidade de Goiás, há uma paralização das possibilidades de ação do fenômeno da participação, as pessoas e os movimentos não se mobilizam o suficiente para promover alterações significativas para a população. Mas, diante do contexto histórico goiano, compartilha-se da ideia de Demo (5) ao apontar que a participação é conquista, é um processo infindável, em constante 'vir-a-ser', sempre fazendo. Não existe participação suficiente, nem acabada.

Se a participação é uma conquista significa que as pessoas que estão envolvidas na constituição do Comitê de equidade deverão estar atentas à dinâmica desse componente político. Construir cotidianamente o fazer e o aprender fazer político derivado do exercício da participação.

Os movimentos sociais cumprem papel importante nesse processo de construção da participação popular devido às suas características de questionadores, de produtores e reorientadores de sua própria história. A educação popular como um processo formativo continuado revela-se imprescindível para afastar a condição de apatia e descrença que recai nos sujeitos de tempos em tempos.

O movimento de Educação Popular foi um a das numerosas formas de mobilização de massas adotadas no Brasil. É possível registrar numerosos procedimentos de natureza política, social e cultural de mobilização e de conscientização de massas, a partir da crescente participação popular por meio do povo (participação geralmente dirigida pelos líderes populistas) até o movimento de cultura popular organizado pelos estudantes. (9) 
A educação popular em saúde pode ser um instrumento de formação eficaz na medida em que busca trabalhar o homem e os grupos envolvidos no processo de participação popular. Fomenta formas coletivas de aprendizado e investigação de modo a promover 0 crescimento da capacidade de análise crítica sobre a realidade e 0 aperfeiçoamento das estratégias de luta e enfrentamento, levando em conta, o saber anterior das classes populares, fazendo com que a partir disso, as pessoas adquiram um entendimento sobre sua inserção na sociedade e no meio ambiente (10).

\section{Concepção sobre participação popular e sua relação com o exercício da cidadania e do direito à saúde}

Para os colaboradores, a participação popular está relacionada à possibilidade de reunir pessoas, discutir e construir a mobilização social. Isto pode ser observado nas falas abaixo.

Participação popular é quando você vai participar de algum [...] onde têm muitas pessoas, onde as pessoas têm várias crenças, várias raças, várias etnias, onde as pessoas vão discutir assuntos, né!? de interesse da comunidade. (P1)

Participação popular para mim é construir o movimento junto com a população, PSF [Programa Saúde da Família], também junto fazendo parte desse movimento que é uma grande maravilha do meu ponto de vista na questão da saúde. (P5) (colchetes nossos)

Participação popular, para mim, significa haver agrupamentos de pessoas que têm várias ideias no mesmo sentido voltadas para a população, na saúde na educação e no meio ambiente. (P2)

Entretanto, para o representante da ANEPS-GO, tal participação está relacionada ao exercício da democracia formal.

Compreendo como sendo participação popular a atuação conjunta e democrática de construir e planejar juntos, sociedade civil, com seus mais variados movimentos e segmentos, e poder público, gestores públicos, as demandas, as necessidades e os caminhos a serem seguidos. (P3)

No que se refere à compreensão dos colaboradores da pesquisa sobre a participação como contribuição para o exercício do direito à saúde, observa-se que todas as falam indicam que tal participação qualifica o direito à saúde. Tal qualidade perpassa pelas seguintes ideias: a) participação permite melhorar o desenvolvimento da saúde, porque a 
população pode indicar o que é de sua necessidade (P2 e P4); b) participação possibilita garantir direitos não diretamente relacionados à saúde, mas que também influenciam nas condições de saúde da população (P1, P3 e P6); c) participação pode fazer com que determinados programas se tornem mais eficazes (P5).

\section{Quadro 1 - Participação e exercício da cidadania: qualificação do direito à saúde}

\begin{tabular}{|c|c|}
\hline $\begin{array}{l}\text { Participação permite melhorar o } \\
\text { desenvolvimento da saúde, porque a } \\
\text { população pode indicar o que é de sua } \\
\text { necessidade }\end{array}$ & $\begin{array}{l}\text { [...] participação é uma forma de toda a população, toda } \\
\text { comunidade, naquilo que é necessário né !? para população, } \\
\text { para que haja um maior desenvolvimento da saúde. (P2) } \\
\text { Claro, é essencial, que a população participe e esteja no } \\
\text { direito a saúde, a população têm direito a saúde (P4) }\end{array}$ \\
\hline $\begin{array}{l}\text { Participação possibilita garantir direitos não } \\
\text { diretamente relacionados à saúde, mas que } \\
\text { também influenciam nas condições de } \\
\text { saúde da população }\end{array}$ & $\begin{array}{l}\text { Sim por que pode estar envolvido, saúde educação, } \\
\text { segurança, tudo pode estar envolvido. Ah, a saúde é um dos } \\
\text { temas mais discutidos né ?! (P1) } \\
\text { [...] Entendemos que as conquistas que tivemos não somente } \\
\text { na área de direitos à saúde, mas também em outras áreas, } \\
\text { educação, relações étnicas etc. se deu por processos de } \\
\text { participação, pressão, negociação e cobrança dos } \\
\text { movimentos sociais. (P3) } \\
\text { [...] Antes tínhamos menos. Hoje temos as pessoas indo às } \\
\text { rádios, nós temos as pessoas buscando os seus direitos, } \\
\text { quando eu digo direitos são todos os que eu disse antes. A } \\
\text { saúde, a educação, em tudo. A saúde não está envolta no } \\
\text { corpo em si, a saúde envolve um monte de coisas. Né !? } \\
\text { Como bem estar físico, emocional. O trabalho também é } \\
\text { importante, por que se você não tiver trabalho, você não têm } \\
\text { renda, assim não têm como buscar a saúde. (P6) }\end{array}$ \\
\hline $\begin{array}{l}\text { Participação pode fazer com que } \\
\text { determinados programas se tornem mais } \\
\text { eficazes }\end{array}$ & $\begin{array}{l}\text { Participação popular pode contribuir sim, de muitas } \\
\text { maneiras, e a população pode ajudar a melhorar, dando suas } \\
\text { opiniões. Fazendo suas reivindicações no que pode estar } \\
\text { deixando a desejar, para que o programa tenha mais } \\
\text { eficácia. (P5) }\end{array}$ \\
\hline
\end{tabular}

Fonte: Entrevistas com os participantes do projeto de extensão, 2014.

Percebe-se que o processo de participação tem sido construído recentemente no contexto do Estado de Goiás, devido às características históricas da região, desde o século XIX, no centro-oeste brasileiro, que a estrutura política esteve permeada pelo fenômeno do coronelismo.

De acordo com Palacin (11) 'o termo coronelismo denota uma estrutura política caracterizada pela força dos coronéis'. Os coronéis, além de deterem o poder político, 
também eram controladores da economia e exerciam forte influência entre os trabalhadores locais, ao ponto de conseguirem manipular o direito ao voto.

O historiador Palacin (11) aponta, ainda, que os coronéis sempre estiveram associados ao domínio da posse da terra, mediante o latifúndio, o domínio dos homens que dela dependiam, dentre eles, os agregados, os peões, os meeiros. $E$, assim, em sendo um elemento controlador de riquezas e pessoas, geralmente, pelo uso da força física e psicológica detinha nas mãos o poder de dizer o direito, dizer o certo e o errado de acordo com os interesses das oligarquias hegemônicas do período.

A figura da participação somente aparecia por meio do exercício do voto. Sabe-se que o direito de sufrágio estava contaminado pelos interesses dos coronéis em seus 'currais eleitorais'. O coronel comanda os votos de seu 'colégio eleitoral'. Intimida, anula urnas, destrói atas e documentos eleitorais (12).

Para o eleitor, a ideia de votar estava ligada a retribuição de favores econômicos, políticos, sociais, tais como apadrinhar alguém ou dar auxílio aos doentes, por exemplo. 'O ato de votar num candidato indicado por um coronel não é aceitar passivamente a vontade deste; é dar conscientemente um voto a um chefe poderoso, de quem já se obteve algo, ou se almeja obter algo' (13).

Nessa temporalidade histórica, a participação esteve sufocada pela força do sistema coronelístico e, consequentemente pela ausência de formação dos sujeitos, ausência de um Estado comprometido com as questões populares. Lembrando Pateman (1) a independência econômica dos sujeitos e a igualdade seriam os elementos capazes de modificar o mínimo exercício de participação para um grau mais elevado na medida em que os sujeitos se tornam autônomos.

\section{Contribuição da Roda de Conversa para a construção da participação popular em saúde na Cidade de Goiás.}

Para os colaboradores a Roda de Conversa na Cidade de Goiás contribuiu para informar, formar e mobilizar os participantes. 


\section{Quadro 2 - Contribuição da Roda de Conversa realizada na Cidade de Goiás}

\begin{tabular}{|l|l|}
\hline $\begin{array}{l}\text { Contribuição para iniciar } \\
\text { movimento de mobilização popular }\end{array}$ & $\begin{array}{l}\text { Foi o primeiro passo, a sementinha que não existia e que } \\
\text { aconteceu, só tá faltando nascer, só isso, e florir, só isso. (P2) } \\
\text { Temos que chamar a participação dos líderes de bairros, das } \\
\text { igrejas, do MST, do movimento de negros e negras, enfim todo } \\
\text { mundo. Para formar todo mundo e levar o movimento pra frente. } \\
\text { (P1) }\end{array}$ \\
\hline Contribuição formativa & $\begin{array}{l}\text { Através da roda de conversa nós vemos os programas que estão } \\
\text { sendo desenvolvidos, vemos os resultados, vemos os pontos } \\
\text { positivos, encaminhar, vemos também pontos negativos que } \\
\text { podem deixar de ser concluídos, com coisas que podem estar } \\
\text { melhorando muito mais. (P5) }\end{array}$ \\
$\begin{array}{l}\text { Foi primordial, pena que tivemos pouca contribuição dos } \\
\text { estudantes. Tivemos mais participação dos professores, do } \\
\text { pessoal da saúde e dos movimentos sociais. Foi importante por } \\
\text { que os estudantes hoje, como se diz, formou em direito têm o } \\
\text { peso muito importante, pena que assim, eu não posso dizer com } \\
\text { muita propriedade, mas as pessoas não têm noção ainda de quão } \\
\text { importante é o advogado, você conhecer de leis, por que nós } \\
\text { somos regidos por leis, e às vezes as pessoas não sabem a } \\
\text { realidade das leis, e nós podemos buscar nossos direitos, e } \\
\text { populaçãonão conhece seus direitos, então não têm como buscar } \\
\text { participação popular se não se conhece os seus direitos. O } \\
\text { conhecimento ali criado foi importante para aumentar a a } \\
\text { participação popular. Deve haver mais rodas de conversa. (P6) }\end{array}$ \\
\hline
\end{tabular}

Fonte: Entrevistas com os participantes do projeto de extensão, 2014.

Para o representante da ANEPS-GO, a Roda teve especial contribuição para os servidores da saúde, que puderam avaliar as condições de trabalho e expressar expectativas de mudanças.

Pelas três rodas que já aconteceram da ANEPS, vejo como sendo positiva, os servidores da saúde responderam bem ao chamado, houve uma provocação em relação as condições de trabalho bem como expectativas de desejos de mudanças dessas realidades. (P3)

A dinâmica das rodas teve embasamento metodológico fundamentado na produção científica freiriana, uma abordagem que respeita a cultura, o diálogo, as práticas populares, a ancestralidade e suas trajetórias singulares e coletivas.

Os grupos que participaram do evento em Goiás trouxeram consigo para o compartilhamento, suas histórias, suas necessidades, suas experiências, a partir da troca de conhecimentos comunidade e universidade. 
Esses elementos são importantes para o exercício político de participar porque oportuniza ampliar o debate e encontrar soluções para os problemas da comunidade de forma aberta.

Para os colaboradores da roda de conversa foi fundamental que o evento tenha acontecido porque contribuiu com a mobilização das pessoas e, ainda, possibilitou o processo formativo. Nota-se a importância do papel da universidade e suas ações de extensão voltadas para a comunidade.

O projeto de extensão Saberes, Fazeres e Sabores: encontros de práticas integrativas da Política Nacional de Educação Popular e Saúde (PNEPS) em Goiás e articulações na região centro-oeste se propôs, por meio de esforços da comunidade acadêmica, contribuir com a construção de um comitê de equidade no município que atendesse aos princípios formulados a partir da política nacional, mas, com amparo na contribuição dos profissionais de saúde, dos usuários do SUS.

A participação desses atores sociais no processo de construção do Comitê é fundamental devido ao fato de que o Comitê tem, dentre outros objetivos, estimular a formação política e participativa da comunidade e movimentar-se no sentido de promover um controle social das ações dos gestores,

\section{Conclusão}

A pesquisa proporcionou a melhor compreensão sobre a questão da participação a partir da construção do Comitê de Equidade na Cidade de Goiás, Goiás. Permitiu visualizar o alcance da Política Nacional de Educação Popular em Saúde diante das atividades do projeto de extensão 'Saberes, Fazeres e Sabores: encontros de saberes e práticas integrativas da política nacional de educação popular e saúde em Goiás e articulações na região centro-oeste: encontros de saberes e práticas integrativas'.

A participação é um instrumento de soberania popular que aparece na arena política como um elemento de controle e de exercício de cidadania. Contudo, nesse mesmo contexto político, existem divergências no que tange à aceitação ou não da participação do povo nas decisões políticas das mais diversas áreas.

A participação permite o desenvolvimento da saúde porque os usuários podem indicar as reais necessidades da comunidade. Podem aumentar a eficácia dos direitos sociais já que influenciam no controle das políticas. Contudo, essa mesma pesquisa identificou 
limitações para a construção do Comitê de Equidade, na Cidade de Goiás, Goiás. A mais significativa das limitações está permeada pelas características de submissão do povo ao controle político pautado nas práticas coronelísticas, tais como o apadrinhamento, os cabides de empregos, troca de favores por votos. Essas práticas, tradicionalmente e largamente utilizadas em Goiás, ainda são entraves para o exercício da participação popular.

Tem-se então, que a educação, quer seja formal ou informal, pode vir a tecer um distanciamento de tais práticas políticas na dinâmica social dos goianos. Ainda, acredita-se que a presença de instituições de educação superior na localidade tem sido um elemento que contribui com a promoção de nova postura política e social. Paulatinamente, acontece um rearranjo na mentalidade das pessoas. A construção do conhecimento e sua expansão têm contribuído para a formação dos sujeitos e para que se desvencilhem das amarras que historicamente os prendem.

\section{Referências}

1 - Pateman C. Participação e teoria democrática. Rio de Janeiro: Paz e Terra; 1992.

2 - Pio C, Porto M. Teoria política contemporânea: política e economia segundo os argumentos elitistas, pluralistas e marxistas. In: Rua MG, Carvalho MIV, organizadores. $O$ estudo da política: tópicos selecionados. Brasília: Paralelo 15; 1998.

3- Costa HO. Democracia e Participação na Teoria Pluralista. Cronos. 2007 [Acesso em 1ํㅡㄴ set 2014], 8(1):215-228. Disponível em:

http://http://www.dhnet.org.br/direitos/militantes/homero costa/homero democracia partici pacao t pluralista.pdf ISSN 1988-5560.

4 - Dahl R. Um Prefácio à Teoria Democrática. Rio de Janeiro: Jorge Zahar Editor; 1989.

5 - Demo P. Participação é conquista: noções de política social participativa. São Paulo: Cortez; 1998.

6 - Brasil. Ministério da Saúde Secretaria de Gestão Estratégica e Participativa. Política Nacional de Educação Popular em Saúde. Brasília, 2012. [Acesso em 1ํ set 2014].

Disponível em: http://www.crpsp.org.br/diverpsi/arquivos/PNEPS-2012.PDF

7 - Rousseau JJ. Do Contrato Social. São Paulo: Martin Claret; 2003.

8 - Yin RK. Estudo de Caso. Tradução e síntese: Prof. Ricardo Lopes Pinto. Adaptação:

Prof. Gilberto de Andrade Martins. Porto Alegre: Bookman; 2001. 
9 - Freire P. Conscientização: teoria e prática da libertação - uma introdução ao pensamento de Paulo Freire. São Paulo: Centauro; 2008.

10 - Brasil. Ministério da Saúde. Secretaria de Gestão Estratégica e Participativa. Caderno de Educação Popular em Saúde [Internet] Brasília, 2007. [Acesso em 9 ago 2014].

Disponível em:

http://bvsms.saude.gov.br/bvs/publicacoes/caderno educacao popular saude p1.pdf ISSN 9788533414136.

11 - Palacín L. História de Goiás (1722 - 1972). Goiânia: UFG; 1989.

12 - Ferreira GTS. O Coronelismo no Estado de Goiás (1889 - 1930): as construções do fenômeno pela história e pela literatura. [Dissertação]. Goiânia: Departamento de História, Universidade Federal de Goiás; 1997.

13 - Queiroz MIP. O Coronelismo, uma interpretação sociológica. In: B. Fausto, organizador. História Geral da Civilização Brasileira. O Brasil Republicano. Rio de janeiro: Civilização Brasileira (vol. 3). São Paulo, Difel; 1975. 